\title{
The Causes and Solutions on the Problems of Internet Education for Children
}

\author{
Fan Jun-qing* \\ Department of Preschool Education, Normal College of Beihua University, Jilin, Jilin, China \\ *fanjq20070128@126.com
}

\begin{abstract}
Children's Internet education as a product of the age has an important influence on the growth and development of children which is beneficial in some aspects, but unfavorable in some aspects. This paper analyzes and explores the causes for the problems of Internet education for children which includes cognitive dislocation to Internet education for children, negative family environment and poor parents-child attachment, overburdened learning tasks and the lack of playmates and then on this basis puts forward the solutions to solve the problems of Internet education for children. The solutions are as follows: treating Internet education rationally, creating a good environment for children, paying enough attention to children and loving children with all your heart, home-school cooperation and home-school co-education.
\end{abstract}

Keywords: children, Internet education, problems, causes, solutions

\section{PREFACE}

With the advent of the electronic age, computers have gradually entered urban households and even some rural households also have computers. The research on the influence of network culture to moral education in the school and its countermeasures completed by Lao $\mathrm{K} \mathrm{S}$ in Beijing normal university reveals that $76.7 \%$ of students' families in Beijing buy computers and $69.2 \%$ of students' families surf the Internet at home. The 18th statistical report on Internet development in China in 2006 reveals there are 123 million Internet users in China and 30 million Internet users among the 200 million primary and middle school students. With the improvement of living standard, computers have become an indispensable part of family for work, study and leisure. With the improvement of living standard, computer has become an indispensable part of family work, study and leisure. Even if some families don't have computers, almost all adults have a smart-phone and students in the upper grades of primary school and most students in the middle and high school also have smart-phone. However, the Internet has such a high penetration in children's life and study and the public has favoured "high-tech" products. All these may lead to some problems in using the Internet, such as Internet children, children addicted to the Internet. Similar incidents have been reported sometimes and many parents and teachers are at the mercy of such questions. Parents and teachers feel kids fall into Internet too deep and even some parents said: "help my child!" Of course, some parents are unaware that their children are overexposed to the Internet. Many children are near-sighted not because of studying too hard, but because of spending too much time on the Internet. A series of problems make strengthening the guidance for children's
Internet education become the current important topic. This paper will explore and elaborate the causes and solutions on problems of children's network education.

\section{CAUSES}

\subsection{Cognitive Dislocation to Internet Education for Children}

I think one of the most important reasons is the misunderstanding of computer and Internet. Many people, including teachers and parents think computer is high-tech products even omnipotent machines, so the computer is deified. Some parents worry that their children are behind the times and buy computers for them to play games. Under the wrong understanding and guidance, children are addicted to computers. Children tend to form a blind worship and dependence on computers and the Internet and become addicted to the Internet by chronic attachment and overexposure. Because the Internet has the characteristics such as audiovisual combination, three-dimensional, dynamic participation and interactivity, children will find more stimulating content on the Internet compared with boring knowledge in the book and are easy to be addicted to the Internet and fall into the Internet unconsciously.

\subsection{Negative Family Environment and Poor Parents-child Attachment}

Some studies have shown that contradictory of family environment and negative attachment relationship have 
significant influence on adolescent Internet addiction. Inharmonious behaviors among family members such as conflict, quarrel and even attack make children learn negative emotions and behaviors. Children are more likely to feel lonely, helpless, depressed, anxious and disgusted and turn to the Internet as a "haven" to escape quarrels and find peace and comfort. Meanwhile, lack of parents' companionship and education to children and their neglect to children is one of the important reasons why children are addicted to the Internet. Some studies have shown that the external causes of left-behind children's Internet addiction are mainly parent-child relationship, including parent-child separation and parent-child conflict. Long-term separation between parents and children makes the intimacy and dependence weaken slowly. It's easy to breed parent-child estrangement and even parent-child conflict. In turn, parent-child conflict has a negative impact on the parent-child relationship of left-behind children and children's helplessness, loneliness, anxiety and even anger indirectly lead to Internet addiction. A series of crime cases in Internet cafe indicate the suspect are young and many children's parents are divorced or busy with their jobs. If the relationship between husband and wife is not harmonious, some children prefer to complain about their frustrations and grievances in Internet or let off steam by online games. Some parents are busy with their jobs to care for and educate their children.

\subsection{Overburdened Learning Tasks and the Lack of Playmates}

At present, most students have to attend some interest classes after school in addition to homework. But interest class after school also assigns a lot of homework in order to highlight the educational effect. The result is there is little time for entertainment and leisure in a heavy academic burden for students. Nowadays, most students feel that their schoolwork is heavy and they have little time to relax so students are easy to turn to computers and the Internet as the best way to relax. When asked what they would like to do most, many students think it is playing with computers without hesitation. After follow-up questioning they think it's easy to relax in the Internet where they don't have to study or worry about homework. So to speak, many students consider the Internet as a platform to relieve pressure, release their inhibitions and find freedom.

Lack of playmates is also one of the reasons why children like the Internet. Now most children are the only child in the family and have no playmates of the same age while most parents have to work and rural parents even have to go out to work as migrant worker. Therefore, parents do not have enough time to accompany and play with their children. Children in big cities who tucked away in tall buildings have few playmates to play with so have to stay with their grandparents or babysitters. It is well known that peers are the best playmates and promoters for growth. So The children who have private computers tend to spent those lonely hours on computers and the Internet and the newness and figurative of computers also appeal to these lonely children.

Since the Internet brings so much trouble and poses such a great challenge to home education and school education and children, especially those in the lower grades, are susceptible to external influences, Whether Internet education should be carried out and how we carry out Internet education if necessary with the advent of the electronic age.

\section{CONCLUSION}

\subsection{Treating Internet Education Rationally}

Internet education for children is inevitable as a trend of the times. The frequency of children's exposure to the Internet can be determined and controlled by people, especially as children's teachers and parents. Because people have subjective initiative and all problems are caused by people, not by things which are manipulated and controlled by people. Whether Internet education for children is meaningful? What's the meaning? What role does the Internet education play in children's growth and development? It all depends on people, depends on education and guidance from children's teachers and parents.

Tell your child to use the computer and the Internet properly. In many cases, computers can work for human beings and greatly raised the production efficiency and social productive forces. Especially when electronics are so plentiful and easy to use, adults should tell children you can use computers and even help them learn how to use them when necessary to supplement the limitations of resources and tools in children's books and life. But it's also important to tell children that computers and the Internet aren't omnipotent, it's just one of the tools in our lives just like a pencil when writing and a brush when drawing and it only works in certain situations, not all the time. Meanwhile, adults should teach children how to treat computers and the Internet critically and critically and let them know you can look up information and get information timely by computers and the Internet and also need to find reference books to obtain comprehensive accurate and accurate information or experience in real life. You can play online games which can make you relaxed and happy in your spare time, but you have to go out of the room and play with your classmates and good friends if you want to be happy forever. You can surf the Internet and tell your friends in Internet when you are in a bad mood, but it is more important is to sum up the experience and know how to deal with similar problems in the future or you can also ask your teachers and parents for help if you can't figure it out. There are funny things in Internet, but some pages and content are not suitable for children. We should also observe the etiquette of the Internet even in the virtual world of the Internet and should not do whatever you 
want because of the freedom and anonymity of the Internet.

\subsection{Creating a Good Environment for Children, Paying Enough Attention to Children and Loving Children with All Your Heart}

Teachers and parents should identify and block some content that may be corrosive to children in the Internet. The American scholar professor who has put forward the disappearance of childhood believes that children have no childhood in the age of television media and television culture has gradually banished childhood. In fact, childhood is born of reading in the age of printing and children can learn about the world by reading children's books. However, what belongs to the adult is shown in front of the children in the TV media and their childhood is lost in adult-controlled television because children are exposed to adults' secrets too early. The Internet as a kind of media is bound to make adult culture squeeze into children's living space too early. Therefore, the Internet of household and school should be adjusted and restricted appropriately to filter out content which isn't suitable for children ahead of time.

At the same time, parents should try their best to create a warm and happy environment for children so that children live in a family where the spirit is rich, their mood is cheerful, their feeling is bold and unrestrained and their psychology is safe. Emotion is extremely important, especially for young children. Some counseling and psychotherapy traces psychological problems at certain stages of life back to childhood. This suggests that childhood experience has a great influence on people's long-term development. Therefore, parents should find a way to solve the problem as soon as possible and create a warm and comfortable home for children, try their best to accompany their children rather than as a bystanders or absent characters, communicate with your children in an equal and democratic way and give your child enough respect, attention and love. This series of practices can help children get rid of loneliness, helplessness and anxiety and open their hearts to their parents instead of being addicted to the virtual Internet.This requires parents to learn more while media and social organizations provide guidance and education for parents to help them play the role of parents.

\subsection{Home-school Cooperation and Home-school Co-education}

Home-school communication and collaboration are also crucial. Schools should know the students' family environment, family education philosophy and the current situation of family education, communicate with parents about all aspects of the students and give appropriate guidance and advice on family education when necessary. It's hard to solve the problems of children's Internet addiction either your family or your school. Therefore, family and school should complement each other by good communication and cooperation to form a unified and effective educational philosophy and solutions between school and family in order to strengthen education and guidance in understanding the Internet rationally. So, the cooperation between family and school can effectively solve the problems of children's Internet addiction and promote their growth and development.

\section{ACKNOWLEDGMENT}

This work is the subject of the 13th five-year scientific research plan of Jilin Province Education Society and the subject is the study on curriculum construction and implementation strategy of children's social affective ability （JLXH13520496）.

\section{REFERENCES}

[1] Luo, H P, Peng, Y. (2008) Relationship of Intern et addiction and family environment and attachment of the youth. Chinese Journal of Clinical Psychology, 16:319-320.

[2] Gao, G S, Wang, X L. (2006) Survey on behavi or problems among children involved in Internet. Pra ctical Preventive Medicine, 6:1444.

[3] Guo, J. (2006) An exploration into children's ex position to the E- Age Internet. Journalism and Mas s Communication Monthly, 6:101.

[4] Chen, H H. (2009) Review and discussion on co ncept and diagnostic criteria of Internet addiction. In dustrial \& Science Tribune, 8:185-188.

[5] Wang, Y F. (2005) Strategies for children's netw ork injury and protection: building a network system for protecting children. Teacher's Journal, 2:36-38.

[6] Zhou, M R, Zhu, G W. (2019) Causes and strate gies on the problem of Internet addiction for left-beh ind children. Liaoning Education, 2:12-14.

[7] Cai, L Y. (2010) Research on network injury an d protection for children from comparative perspectiv e between China and the United States. E-education Research, 204:31-35.

[8] Jiang, Y E. (2013) Improving family-oriented co mmunity protection networks for children. Collection of Women's Studies, 118:61-62.

[9] Huang, R S. (2019) Cultivating teenagers' cultura 1 confidence and media literacy in the new media er a. China Radio \& TV Academic Journal, 334:72-73. 